Para citar este artículo / To cite this article:

MANGAS NAVARRo, Natalia Anaís (2020), «Nuevas fuentes para la poesía de Pedro de Gracia Dei», Revista de Cancioneros Impresos y Manuscritos, 9, pp. 44-75. https://doi.org/10.14198/rcim.2020.9.03

\title{
NUEVAS FUENTES PARA LA POESÍA DE PEDRO DE GRACIA DEI
}

\section{NEW SOURCES FOR THE POETRY OF PEDRO DE GRACIA DEI}

\author{
Natalia Anaís Mangas Navarro \\ Universitat d'Alacant \\ nataliamangas_4@hotmail.com \\ https://orcid.org/0000-0003-1505-7512
}

Este trabajo se enmarca en el proyecto Cancionero, Romancero y Fuentes Impresas del Ministerio de Economía, Industria y Competitividad (FFI2017-86313-P), financiado por la Agencia Estatal de Investigación (AEI) y el Fondo Europeo de Desarrollo Regional (FEDER).

\section{RESUMEN}

Con el objetivo de realizar un catálogo completo de las fuentes poéticas de Pedro de Gracia Dei, este trabajo ofrece el estudio material y textual de cuatro testimonios que no recogen los principales repertorios dedicados a la indexación de fuentes y textos castellanos medievales. Ello nos permite, por tanto, ampliar los materiales que presentan esos catálogos, al mismo tiempo que avanzamos en el conocimiento de la obra en verso de este autor. Se trata de cuatro fuentes manuscritas de naturaleza y contenido muy diverso, que añaden nuevos datos para la obra poética de Gracia Dei y evidencian el complejo proceso de transmisión textual en el que se inserta.

PALABRAS ClAVE: Pedro de Gracia Dei; fuentes manuscritas; transmisión textual; corpus poético.

\section{ABSTRACT}

In order to elaborate a complete catalogue of Pedro de Gracia Dei's poetry sources, this work presents the material and textual study of four testimonies that are not 
included in the main repertories dealing with the indexation of sources and medieval Castilian texts. This allows us, therefore, to broaden the materials which are present in these catalogues, simultaneously advancing in the knowledge about the poetry of this author. We are referring to four manuscripts whose nature and content are very diverse. However, they all add new information about the poetic work of Gracia Dei and witness the complex textual transmission process in which it can be inserted.

KEYWORDS: Pedro de Gracia Dei; manuscripts sources; textual transmission; poetic corpus. 
El punto de partida para un primer acercamiento a los testimonios poéticos de Pedro de Gracia Dei lo constituye, sin lugar a dudas, El cancionero del siglo XV de Brian Dutton (1990-1991, II: 369-370; II: 424; III: 52), que, para su obra, documenta cuatro fuentes: MN57, MP2, NH6 y 89*GD. Se trata de testimonios muy diferentes entre sí, concebidos cada uno con diversos intereses: MN57 es una fuente historiográfica y solo transmite dos textos de Pedro de Gracia Dei - los que, efectivamente, se insertan en la línea general del manuscrito-; ${ }^{1} \mathrm{MP}^{2}$ es una rica y heterogénea fuente poética en la que Dutton identifica cuatro obras de nuestro autor; ${ }^{3} \mathrm{NH} 6$ se consagra como uno de los testimonios poéticos de Pedro de Gracia Dei más importantes, no solo por la cantidad de composiciones que contiene, ${ }^{4}$ sino porque se trata de una fuente unitaria del poeta, característica poco habitual en la transmisión de su obra en verso; ${ }^{5}$ y $89 * G D$ es un incunable que se limita a transmitir la Criança y virtuosa doctrina. ${ }^{6}$

1 Para un completo estudio material del códice, así como del análisis de los textos y transcripción, por primera vez, de ID 8324 V 1942, una versión de una obra de Gracia Dei, remito a Mangas 2019: $151-165$.

2 Contamos con el estudio y edición de este cancionero en Labrador et al. 1984 y 1986 . Está catalogado también en López Vidriero (1994, I: 270-289).

3 No obstante, si atendemos a la disposición de los textos, en el cancionero se le atribuyen otras tres breves composiciones, ya que se insertan seguidamente junto a las cuatro que identifica Dutton bajo un mismo apartado titulado "Gracia Dey»: el primero, A la muerte del rey Don Philipe (f. 135 $\left.{ }^{\text {ra }}, 1 \times 10\right)$; el segundo de ellos bajo el título Lo que hicieron el rey don Fernando y la reyna doña Ysabel (f.135 ${ }^{\text {ra }}-135^{\text {rb }}$, 1x10), que se corresponde con la copla real con la que culmina la obra ID 1942 en algunos testimonios; finalmente, otra estrofa encabezada por el título Adversidades, aunque, probablemente, se insertó a colación de la anterior. De hecho, López Vidriero cataloga un total de siete composiciones atribuidas a Gracia Dei (1994, I: 278), las cuatro que documenta Dutton más estas tres.

4 Identifica un total de siete textos: ID 6964 ${ }^{\text {bis }}$ | 1942, ID 1942, ID 6965 $5^{\text {bis }}$, ID 6966 ${ }^{\text {bis }}$, ID 1943 Y6966 bis $^{\text {, }}$ ID 1941 e ID 6967. Además de Brian Dutton, da noticia sobre este manuscrito Faulhaber (1983, II: 447450).

5 De más de la veintena de manuscritos que recogen poemas de Pedro de Gracia, solo cinco son monográficos: NH6, los mss. 3231, 5911 y 18045 de la BNE y el códice 50-I-41 de la Biblioteca da Ajuda.

6 Testimonio único, impreso ca. 1486 en el taller salmantino de Juan de Porras. Se conserva en la Biblioteca Nacional de España con signatura INC/1272. Mi tesis doctoral, titulada La «Criança y virtuosa dotrina» de Pedro de Gracia Dei: estudio y edición crítica, se defenderá en 2020 en la Universidad de Alicante. 
El incuestionable valor de El cancionero del siglo xV no implica, en cualquier caso, que no tenga, a día de hoy, importantes limitaciones, por sus casi tres décadas de antigüedad y por las posibilidades que ha facilitado la era digital en la que nos encontramos. A solventarlas ayuda en buena manera, aunque no sea específica de poesía, la Bibliografía Española de Textos Antiguos (BETA). Su carácter electrónico permite una continua actualización e inmediata difusión de sus resultados, de manera que en las últimas tres décadas se ha completado con materiales que Dutton desconocía al elaborar su catálogo, entre los que se encuentran 18 nuevas fuentes poéticas de Pedro de Gracia Dei, que debemos añadir a las 4 catalogadas por él:

FONDOS BIBLIOGRÁFICOS

Biblioteca Nacional de España

Biblioteca Lambert Mata, Ripoll

Biblioteca da Ajuda

Biblioteca Nacional de Portugal
SIGNATURAS

Mss. 1367, 3231, 3346, 3449, 3564,

$3769,5911,6175,7864,9087,12612$,

18045,18053 y 18380

Ms. h. II. 21

Ms. 69

Ms. 50-I-41

COD. 1155

Si bien BETA supone un importante complemento a Dutton, más allá de que revisemos y/o confirmemos sus descripciones de los testimonios de Gracia Dei, no podemos limitarnos a ella y acabar ahí el proceso de catalogación. Así, gracias a la revisión de catálogos manuales y en línea de diferentes bibliotecas, he podido identificar otras cuatro fuentes para la obra poética de Gracia Dei: el manuscrito II/660 de la Real Biblioteca; el códice F/30 del Monasterio de las Descalzas Reales de Madrid; el códice 9/271 de la Real Academia de la Historia; y una copia tardía que se encuentra en la Biblioteca Capitular de Sevilla, con signatura 58-4-6. Su catalogación y estudio es el objetivo principal de este trabajo. ${ }^{7}$

7 El manuscrito II/660 de la Real Biblioteca y el 9/271 de la RAH están digitalizados en las páginas de sus respectivas bibliotecas, no así las fuentes del Monasterio de las Descalzas Reales y la que se custodia en la Capitular de Sevilla. 
MANusCrito II/660, ReAl Biblioteca, MadRid

Conocemos a dos de sus antiguos poseedores gracias a los exlibris que contiene. El primero de ellos lo encontramos en la parte superior izquierda de la contracubierta anterior, que se corresponde con el exlibris real de la época de Carlos IV y Fernando VII (López Vidriero 1994, I: 314), aunque generalmente se asocia al segundo de ellos, tal y como consta tanto en el catálogo en línea de la Real Biblioteca, como en su base de datos dedicada a los exlibris. Se trata de un complejo grabado con escudos cuartelados de Aragón, Castilla, León, Austria, la Borgoña moderna y la antigua, Brabante, Flandes y Toscana, amén de diversos motivos, como el collar de la orden de Carlos III. ${ }^{8}$ El otro exlibris se localiza en la segunda hoja de guarda anterior y durante un tiempo se ha asociado a la figura de Mayáns y Siscar (López Vidriero 1994, I: 314), pero, en realidad, se corresponde con el de Joaquín Ibáñez García, identificación que encontramos ya en el catálogo informatizado. ${ }^{9}$ En el año 1950, la directora de la Real Biblioteca, Matilde López Serrano, identificó a este bibliófilo y su exlibris en unos documentos que le atribuían el cargo de deán de Teruel, si bien no fue esta la ocupación que ostentaba, sino la de chantre (Ahijado Martínez 2011:7). Gracias a otro documento del Archivo General de Palacio sabemos que el 2 de junio de 1788, un año después de la muerte de Joaquín Ibáñez, el todavía príncipe Carlos compró la librería del chantre de Teruel por un total de 81705 reales de vellón, que le fueron entregados a D. Pedro Leal, Presbítero Testamentario de Joaquín, por D. Josef Narciso Comenge, Tesorero de los Reales Alimentos (Ahijado Martínez 2011: 6-7). La pista del manuscrito se remonta, por tanto, a finales del siglo XVIII, ya que no encontramos en él más datos sobre otros poseedores anteriores a Joaquín Ibáñez y este, a su vez, pudo adquirirlo de diversas maneras: Jaime Lorén (2017: 27) sugiere que en la ciudad de Zaragoza, al amparo de la actividad de la Real Sociedad Económica Aragonesa de Amigos del País, pudo comprar varios libros, aunque el grueso de su biblioteca debió de formarlo en Roma, teniendo

8 Una completa descripción del exlibris real en https://encuadernacion.realbiblioteca.es/exlibris.

9 Para la figura de Joaquín Ibáñez García, véase Ahijado Martínez 2012: 2-5. 
en cuenta la actividad libraria del país y el tiempo que vivió en ella, amén del trato habitual entre los hombres de letras, de compras, donaciones e intercambios.

El manuscrito está encuadernado en pasta gratinada del siglo XVIII ( 212 × 148 $\mathrm{mm}$ ), de «lomera lisa con paletas doradas y tejuelo de tafilete rojo» (López Vidriero 1994, I: 314), donde está inscrito el siguiente título: «LINAGES | Y | BLASONES | P. V». LaS contracubiertas, tanto anteriores como posteriores, son de papel de aguas. Aunque el último folio del manuscrito está numerado como 167, en total hay 162 (202 x 135 $\mathrm{mm}$ ), pues falta el f. 62 , del que quedan restos, y encontramos otro salto de foliación del f. 145 al 150. El manuscrito contiene, además, cuatro hojas de guarda anteriores en la segunda encontramos el título de las obras que contiene el códice, con una tinta y letra diferentes a las que presenta el resto del códice, debido a un mismo copista - y una posterior. Los ff. 29v , 30, 36, 40v $, 53,57,60^{v}, 61^{v}, 68^{v}, 71,74^{v}, 81,87^{v}, 89^{v}, 95,99^{v}$, $125^{\vee}, 144$ y 145 están en blanco.

Algunos folios presentan pautado, pero solo en los márgenes izquierdo y derecho, no superior e inferior, lo que condiciona una caja de escritura de $180 \times 105$ mm -medidas tomadas del f. $3^{r}$. La primera obra del manuscrito está escrita a línea tirada, donde encontramos entre 30 y 32 líneas por plana (ff. $1^{r}-23^{v}$ ). En la segunda de las obras aparecen conjuntamente partes en verso y glosa de manera irregular, por lo que resulta difícil establecer una descripción sistemática respecto a la disposición de los diferentes textos que convergen (ff. $23^{v}-138^{v}$ ). Las composiciones estrictamente poéticas - que, precisamente, son las que pertenecen a Pedro de Gracia Dei- se disponen en una columna centrada, con tendencia de 2-3 estrofas por folio, lo que implica unas 26 líneas en cada plana (ff. 139r-149r). La relación final del manuscrito, aunque está en prosa, también presenta una disposición centrada en el folio, dejando un considerable espacio en los márgenes izquierdo y derecho (ff. 150 ${ }^{\mathrm{r}}-163^{\mathrm{v}}$ ).

Respecto a la fecha de copia, la única referencia temporal que nos permite orientarnos se encuentra en el último texto: 
Relacion de todos los titulados de españa a si de las casas y linaxes de donde son como de las rentas q tienen y donde tienen sus casas y sus estados y de todos los vizcondes adelantados almirantes y priores y de todos los arçovispados y ovispados de españa de las rentas que tienen Año de 1578 (f. 150'). ${ }^{10}$

Podemos establecer, por tanto, el año 1578 como fecha post quem de copia. En cuanto a las filigranas, su localización en la parte central del cosido dificulta la identificación, ya que ninguna de las dos se percibe en su totalidad. Solo se ve con claridad parte de la primera de ellas, localizada en la tercera hoja de guarda anterior: se trata de una mano con cinco dedos - cuatro cerrados y el pulgar abierto- y del dedo corazón sale una estrella de seis puntas; sin embargo, no se ve el resto de la mano, por lo que desconocemos si contiene algún detalle en la palma o la forma de la parte inferior. La otra filigrana la encontramos a lo largo de todo el manuscrito y parece una circunferencia con una cruz latina inscrita (ff. 15-17, 22, 24, 26-28, 44-48, $63,64,66,73,80,84,91-93,100-104,120-124,141-144,150,159)$.

Respecto a la descripción interna, además de los textos de Pedro de Gracia Dei, el manuscrito comienza con el Diálogo del comendador griego Hernán Núñez de Toledo contra los médicos y boticarios (ff. $1^{r}-23^{v}$ ), tras el cual se encuentra la sección dedicada, en parte, a Pedro de Gracia Dei (ff. $23^{\vee}-143^{r}$ ). Desde el f. $150^{r}$ hasta el $163^{\vee}$, se copian las Rentas de los arzobispados. Y, finalmente, los ff. $164^{r}-166^{\vee}$ recogen la Tabla de los linaxes que hay en este libro, dispuestos estos en orden alfabético y con indicación del número de folio en el que se encuentran. ${ }^{11}$ Las composiciones de Gracia Dei son las siguientes:

10 Reproduzco los textos antiguos citados sin regularizarlos, respetando incluso la segmentación de palabras y el uso de tildes que en ellos se hace. Procedo de idéntico modo cuando, en el cuerpo del trabajo, recupero los nombres de los linajes, que transcribo según los usos de escritura de la fuente que examine.

11 Hasta el ff. $137^{\vee}$ y desde el f. $150^{r}$ hasta el final, este testimonio presenta la misma estructura interna que el ms. 12612 de la BNE, desde las rúbricas hasta las anotaciones marginales. 
1. [ff. $23^{\vee}-138^{v}$ ]: estos blasones son | del Licenciado molina que escrivio las | cossas del Reyno de galicia de doban | sacados imprimio año de 1551 | Y DE GRACIA DEY QVE ES | crivio en tiempo de los Reyes cato | licos año de mil y quinientos y | veinte y zinco | Y DE DAMIAN GOES CAVA | Ilero Lusitano en su Hispania do do data de | lano Bleça Españo La que escrivio Año. | 1540 | BLASON D MVCHOS LINA | jes de los illustres de españa y de muchas | ciudades a do se pone El prinçipio de sus nom | bres por avecedario. Ínc: [Abila]: Digo [sic] de avila çercada / por moros astutamente. Éxpl: [...] «Los plancos que ahora Ilamamos polancos de la antigua romana familia de plançis» (linaje de los Plancos, Polancos, sacado de Damian Goes). ${ }^{12}$

2. [ff. 139r-140']: ReY PELAYO. y los que le siguieron (fragmento de ID 1942). Ínc: Pelayo fue restaurante / el oso mato a favila. Éxpl: don fernando e ysavel / los dos bien aventurados (7x10).

3. [ff. $140^{v}-143^{r}$ ]: Pregvntas Que hiço el papa | Julio A graçia dei en las exçelen | çias de la Reyna doña Ysavel. Ínc: Ysavel que dios llebo / quien era pregunto quien. Éxpl: do yaçe tierra con tierra / dios le de santa morada (12x10).

12 Los linajes que pertenecen al Reyno de Galizia del Licenciado Molina son los siguientes: Arceijas, Pradas Vengañas y Reynosos (ff. 25v-26r) y no Andrades (ff. 27v-28r); Baamondes y Biveros (f. 31 ${ }^{r}-\mathrm{v}$ );

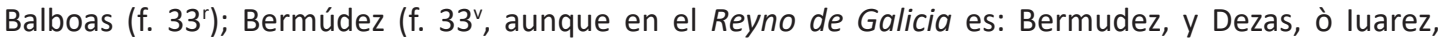
que fueron Turrechaos); Camaños, Aguiares y Bolaños (f. $\left.37^{r}-\mathrm{v}\right)$; Castro (41 ${ }^{\mathrm{r}}$ ); Cadornigas, Temes y

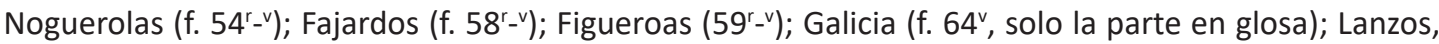
Taboadas y Feiros (f. $75^{r-v}$ ); Losadas (f. 80'); Maldonado (f. 82r); de los Mariños y Loberas y Villamarines (f. 85r); Montenegros y Prados (f. 92v); Moscosos (f. 93'); Mosqueras Lemos, Ocampos y Salgados (f. 93v); Ozores Españas Gayos Varelas (f. 100'-v); Pardos, Celas, Parragueses, Mariñas (f. 103v); Quirogas y

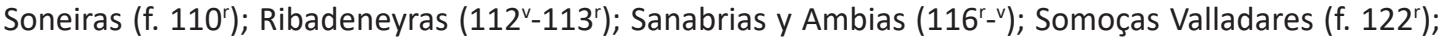
Valcaceres (f. 126r-v); Viedmas (f. $\left.130^{r}-v\right)$; Villandrados (f. $\left.131^{r}-v\right)$; Ulloas (132r) y de los Ponte, Pugas, Galos, Frexomiles, Freiles (f. $138^{r_{-} v}$ ). De Damian de Goes no encontramos obras propiamente dichas, simplemente el copista, en algunos apellidos, incluye algún dato sobre el origen de cada linaje que este autor le atribuye, anotaciones que no superan las 3-4 líneas. Lo encontramos en Aguilas (f. 27v), Barros (35 $)$, Betanquor, Bovedilla, Britos y Bulhones (f. $35^{\mathrm{v}}$ ), Cardona y Coutinhos (f. 37v), Coroneles, Cortes, Coscones, Cotas, Casios, Calvos (f. 45v), Deças (46r) Enriquez, Faleyros (f. 58v), Gallos y Godoy

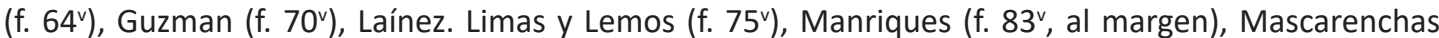
$\left(86^{r}\right.$ ), Merlos y Mellos (f. 94r), Moncada y Munices (f. 94v), Nietos y Norontas (f. 96 ), Padillas (f. 102r), Paçanchas (f. 104v), Rolinsidest, Reinchon y Resendos (f. 112 v), Sandes (f. 115 v), Silvas y Silveyras (f. 117r), Taveyra (f. $125^{r}$ ), Varelas (f. $136^{v}$ ) y Plancos y Polancos (f. $138^{v}$ ). 
4. [f. 143'] : LAS REYNAS HEREDERAS | en españa (ID 1943). Ínc: Hugenia nombre le dio / la loba santos exemplos. Éxpl: ysavel en cada cosa / perfiçion de todas ellas $(1 \times 10) \cdot{ }^{13}$

El caso de la primera obra es un meridiano ejemplo de la confluencia de textos heráldicos y genealógicos de distintas fuentes, de manera que tenemos que discernir entre las composiciones que pertenecen a Gracia Dei y las que se corresponden con los otros dos autores mencionados en la rúbrica - e, incluso, con ninguno de los tres, como ocurre con la primera copla, dedicada a la ciudad de Ávila (f. $24^{r}$ ), que pertenece al Triunfo Raimundino de Juan Ramón de Trasmiera. ${ }^{14}$ Encontramos también los famosos versos que Gómez Manrique mandó grabar en las Casas Consistoriales de Toledo (f. $27^{r}$, «Nobles discretos varones / que gobernáis a Toledo»). ${ }^{15}$

Por su parte, los blasones de Pedro Gracia Dei que contiene esta fuente son extractos de dos de sus obras: los Blasones y armas de los mejores y más principales linajes de Castilla (ID 1941) y los Blasones de ciudades y villas (ID 6967), si bien presentan, en algunos casos, ligeras variantes con respecto a otros testimonios, como es lo habitual en estos dos textos, aunque no afectan a la esencia misma de la estrofa: suelen ser cambios de una palabra por otra o alteración en el orden sintáctico. Sí debemos ser cautos, en cambio, con el primer verso y el último de cada copla referencia a través de la que solemos identificar los textos-, pues son los que están

13 Ni el catálogo de manuscritos de la Real Biblioteca (López Vidriero 1994, I: 314), ni tampoco el informatizado, identifican los textos de Pedro de Gracia Dei: ID 1942, ID 1943 y las Preguntas que hiço el papa Julio... De hecho, atribuyen el éxplicit de 1943 al de la primera obra, los Blasones.

14 Aunque II/660 transmite «Digo de Ávila», es evidente que se trata de un error; al margen de eso, la copla es prácticamente idéntica a la del Triunfo Raimundino: «Digo [sic, Diego] de avila çercada / por moros astutamente / do desmayava su gente / de viandas no avastada/ con treze quesos labiada [sic, librada] / que un noble a su gente dio / avila se defendio / y a los quesos fue cassada» —en el Triunfo se lee «su» en lugar de "fue» en el último verso.

15 Algunos linajes no van acompañados de copla, se deja el hueco en blanco y debajo se añade la glosa. Es el caso de Barros (35r), Cardonigas y Temes (f. 39r), Çarate (f. 39v) Haro (72r), Lazcano (77v), Merlos $\left(94^{r}\right)$, Moncada $\left(94^{v}\right)$, Silvas silveyras $\left(117^{r}\right)$, serveyras $\left(117^{v}\right)$, Solorzano $\left(118^{r}\right)$, Urreta $\left(137^{r}\right)$ Plancos y Polancos $\left(138^{v}\right)$. 
sujetos a más modificaciones y, en ocasiones, pueden llevar a confusión e, incluso, hacernos incurrir en el error de no considerarlos de Gracia Dei. En algunos casos se incluyen dos estrofas para un mismo linaje o ciudad, con mínimas variantes entre ellas y que indico con el número "2» después de la foliación, cuando así sea; otras veces, aunque conviven conjuntamente dos coplas para un mismo linaje o ciudad, solo podemos identificar una de ellas como perteneciente a nuestro autor - a tenor, siempre, de lo que transmiten el resto de testimonios-, en cuyo caso remito a nota.

Los blasones que, por tanto, podemos atribuir a Gracia Dei, son los que se corresponden con los siguientes linajes y ciudades: Acuñas (f. $26^{r-v}, 2$ ); Castilla (f. $\left.27^{r}\right) ;^{16}$ Ayala (f. 29r); Baeça (f. 31v); Burgos (f. 32v); Bracamontes (f. 34r , 2); Bustamantes (f. 35r); Çamora (f. 37v); Castro (f. 41v); de la Cerda (f. 44 r); ${ }^{17}$ Cisneros (f. 44v); Enríquez (f. 46 va); ${ }^{18}$ Córdova (ff. 47v $-52^{v}$ ); ${ }^{19}$ Figueroas (f. 59 ${ }^{r-v}, 2$ ); Girones (f. 66r); Guzmán (f. 70v); Herreras $\left(73^{r}\right.$ ); Horozco (74); Leyba (f. 79r); ${ }^{20}$ Loaysa (f. 79v); Manriques (f. 83v); Mendozas (f. $88^{r}$ ); $;^{21}$ Meneses (f. 90'); Megias (f. 91'r); Ordóñez (f. 97); Osorios (f. 97v);22 Pachechos $\left(101^{r}, 2\right)$; Padillas $\left(102^{v}, 2\right)$; Pimentel (f. 102v, 2 ); Plasencia (f. 103 $)$; Porras (f. 104v); Puerto Carrero (f. 105r, 2); Quiñones (f. 106r , 2); Rey de Castilla (f. 110v); ${ }^{23}$ Portugal

16 Aunque el resto de la obra se organizan alfabéticamente, esta copla aparece sin título dentro de los apellidos que comienzan por «A».

17 Dos coplas para el linaje de la Cerda; identificamos la de Gracia Dei con la que antecede en primer lugar.

18 Se copian dos coplas, a doble columna, pero de Gracia Dei es la de la columna izquierda, que también se transmite en otros testimonios: "Vi dos castillos reales / de oro puestos en alto...».

19 El contenido de este linaje se explica más adelante, por ser de especial interés y complejidad, además del más extenso.

20 El primer verso es diferente a como se transmite en otras fuentes: «En los campos murçianos» vs. «Vi en verde y plateado». Sin embargo, el resto de la estrofa es la misma.

21 Dos coplas en doble columna, la de Gracia Dei es la de la columna izquierda.

22 Dos coplas, la primera de ellas es la de Gracia Dei.

23 Otras dos coplas de Castilla, con alguna variante, que se repiten con la que ya hemos mencionado antes. 
(ff. $110^{\mathrm{v}}-111^{\mathrm{r}}$ ); Salazar (f. $113^{\mathrm{v}}$, 2); Simancas çiudad y apellido (f. $115^{\mathrm{v}}$ ); ${ }^{24}$ Sarmientos (f. 116v , 2); Sosa (f. 118v); Sotomayor (f. 120v); Solier (f. 122v); Toledo (f. 123r); Vigil y Quiñones (f. 127r); ${ }^{25}$ Velascos (f. 128r 2 ) y Vocasnegras (f. 136r, 2 ).

Aunque no lo incluyo en el índice de obras más arriba, para no crear confusión, cabe señalar que la composición ID 1943 aparece en dos ocasiones: una en el lugar que indico, tras las Preguntas que hiço el Papa Julio..., y otra inserta en medio de los Blasones. Entre el apellido Herrera y Horozco, el copista introduce una copla titulada Herederas de España, que se corresponde, en efecto, con ID 1943: empieza con "Yberia», lección que la segunda vez que se incluye la pieza da paso a «Hugenia». ${ }^{26}$ Por tanto, tenemos en esta fuente un caso de duplicación de un mismo texto.

Al margen de los blasones, caracterizados por su reiterativa transmisión en las fuentes poéticas manuscritas de Pedro de Gracia Dei, lo más interesante de este testimonio reside en la presencia de otra de sus obras: las Preguntas que hiço el Papa Julio a Gracia Dei en las exçelençias de la reina doña Ysabel, composición de la que, hasta ahora, solo teníamos constancia a través de un manuscrito de la BNE (ms. 3346, ff. 268 $\left.-269^{r b}\right) .{ }^{27}$ La obra fue editada por Paz y Meliá en sus Opúsculos (1892: 371-378), pero no especifica la fuente en la que se basa. No obstante, a partir de las diferentes lecturas que presenta el manuscrito de la Real Biblioteca con respecto al de la BNE, podemos presuponer que realizó la edición a partir de este último. ${ }^{28}$

24 Se transmite solo la primera quintilla, está incompleto.

25 Aunque agrupa las coplas bajo el título de «Vigil y Quiñones», solo podemos identificarla con el linaje de Vigil, ya que así se transmite en los testimonios que contienen este poema. La copla que se corresponde con el linaje de los Quiñones es otra.

26 El primer verso de esta obra es el que está sujeto a más alteraciones en el proceso de transmisión textual: podemos encontrar tres variantes: "Yberia», "Hugenia» (o «Eugenia») e «Ygeria», aunque predomina la primera de ellas.

27 El manuscrito 12612 de la BNE omite esta parte, pasando de los Blasones a las Rentas.

28 El estudio de las diferentes lecturas desbordaría los límites de este trabajo, ya que comienzan desde la propia rúbrica, pues el manuscrito de la BNE transmite Las XV preguntas... - título por el que es conocida la obra-mientras que en el de la Real Biblioteca se omite el número «xV». 
Aparte de las composiciones, merece especial atención un supuesto pasaje biográfico de Pedro de Gracia Dei que recrea este manuscrito, narrado a colación del linaje de Córdova. Ese relato probaría no solo su vinculación con la ciudad de Salamanca - donde, además, se encontraría su mujer-, sino también el desligamiento de la corte de Fernando el Católico en torno al año 1508 y su posterior relación con el Gran Capitán. No obstante, considero que debemos ser cautos con el grado de fiabilidad de este pasaje, más aún porque intercala composiciones en verso que se le atribuyen a Gracia Dei, cuya autoría hemos de cuestionar, pues la mayoría solo se transmiten en las fuentes que incluyen este relato. ${ }^{29} \mathrm{En}$ total, tendríamos once estrofas: ocho coplas reales y una canción, formada por tres cuartetas:

[ff. 47] Ínc: Al gran capitan honrad / pues por haçañas notorias. Éxpl: y a napoles os gano / dos veces por su persona $(1 \times 10) .{ }^{30}$ [ff. 49v-50'] Ínc: Muy luçido capitan / sello de los doce pares. ${ }^{31}$ Éxpl: digna de goçar mas gloria / que todos juntos goçaron $(4 \times 10) .^{32}$ [f. 51 ${ }^{\text {r-v }}$ ] Ínc: Esta virgen coronada / reyna de reynas mayor. Éxpl: que os guarde en esta jornada / pues q soys su servidor $(3 \times 4) .{ }^{33}$

[f. 51] Ínc: Muy alto rey de los godos / el gran capitan nombrado. Éxpl: que a hecho en buestras Españas / a el me boy queda con dios $(1 \times 10) \cdot{ }^{34}$

29 Los manuscritos 10343 (ff. $197^{r}-200^{r}$ ) y 12612 (ff. 53'-59r) de la BNE, aunque el primero de ellos omite algunos datos, entre ellos dos importantes, como la referencia a la ciudad Salamanca y la posible mujer de Pedro de Gracia Dei.

30 Guarda relación con una copla que se transmite en MP2 y en el ms. 1367 de la BNE: parece una reelaboración a partir del tema de la toma de Nápoles por el Gran Capitán.

31 También a colación del linaje de Córdova, en los mss. 3231 y 5911 de la BNE, podemos encontrar motivos que aparecen en esta estrofa, como el sello de los doce pares.

32 Estas cuatro coplas solo se transmiten, además, en 12612 y en 10343.

33 Esta canción solo la recogen también las tres fuentes que incluyen el pasaje.

34 Copla de un contenido muy sugerente, pues Gracia Dei le dirige el último verso a Fernando el Católico: «a el me boy queda con dios». 
[f. 52'] Ínc: Gano treinta y tres pendones / mas de treçientas banderas. Éxpl: magnanimo y liberal / descanso de graçia dey $(1 \times 10) \cdot{ }^{35}$

[f. 52] Ínc: Si al gran capitan blasonas / saco los yelmos tres dieçes. Éxpl: mucho le sois obligados / los españoles varones $(1 \times 10) .{ }^{36}$

Se trata, por tanto, de una fuente de gran valor textual, debido a la amalgama de composiciones poéticas de Gracia Dei que en ella convergen, pero también constituye una interesante referencia en cuanto a los datos de posible carácter biográfico de nuestro autor que, de ser ciertos, nos permitirían esbozar parte de su trayectoria vital, marcada por la desvinculación de la corte de Fernando el Católico y su paso al servicio del Gran Capitán.

\section{Manuscrito F/30, Monasterio de las Descalzas Reales, MAdRID ${ }^{37}$}

La fundación del Monasterio de las Descalzas Reales se remonta a mediados del siglo XVI, cuando Juana de Austria, hija de Carlos V, regresó a España por mandato de su padre para hacerse cargo del gobierno de Castilla en 1554, tras quedarse viuda al morir Juan Manuel de Portugal. La labor comenzó a instancias de su confesor, el jesuita San Francisco de Borja y, mientras terminaban las obras, las primeras monjas, venidas del Convento de Santa Clara de Gandía, se ubicaron en Valladolid durante dos años. De vuelta a Madrid, esperando a que finalizaran los trabajos en el Monasterio, se hospedaron en la casa del Obispo de Plasencia durante otros dos años. Finalmente, el 15 de agosto de 1559 se trasladaron definitivamente al actual Monasterio.

En base al estudio de García López (2003), podemos distinguir cinco fondos documentales en el archivo del Monasterio: el de Fundaciones de Doña Juana, dividido,

35 Esta copla se transmite también en MP2 y en el ms. 1367 de la BNE, aunque difieren en el último verso: "gran celador de la ley».

36 La recogen también los ms. 3231 y 5911 a colación del linaje de la ciudad de Córdoba.

37 Agradezco a Ana García Sanz, conservadora del Monasterio de las Descalzas Reales y de Tordesillas, su predisposición por agilizarme el trabajo y permitirme consultar el ejemplar físicamente en dicha institución. 
a su vez, en cuatro subfondos - el referido a la documentación relativa a la gestión, control y gobierno de todas las fundaciones de doña Juana, el del propio Monasterio, los documentos de la Fundación Principal del Culto Divino, la Capilla y, finalmente, el subfondo dedicado al Real Hospital de la Misericordia-; el fondo segundo, formado por aquellas fundaciones particulares de Memorias pías y festividades religiosas; el tercer fondo lo constituye la Testamentaría de la Emperatriz María; el cuarto fondo, dedicado a la Real Congregación de Nuestra Señora del Milagro y, finalmente, un quinto fondo intitulado «documentación inconexa». Debido al contenido del manuscrito, es lógico que no podamos incluirlo en alguno de los cuatro fondos dedicados a documentación estrictamente relacionada con el Monasterio. Aunque García López tampoco lo incluye dentro del quinto fondo, es a él al que deberíamos adscribirlo, pues es probable que el manuscrito sea una pertenencia personal, como muchas otras de las que llegaron al Monasterio «como integrantes de las dotes de algunas monjas profesas de origen noble» (García López 2003: 26). ${ }^{38}$

El manuscrito está encuadernado en pergamino marrón oscuro (287 x 198 mm), con restos de correíllas, tanto en la parte superior como inferior de la cubierta. La encuadernación es totalmente lisa: no encontramos título en el lomo, ni ningún adorno o sello identificativo que nos permita indagar en antiguos poseedores - ni en ninguna otra parte del manuscrito. Tampoco contiene título en su interior, ni siquiera al comienzo de la primera obra o en los primeros folios, como pudiera ser lo habitual. No obstante, tanto en el catálogo físico como en el informatizado se identifica con el siguiente título entre corchetes: Libro de linajes dirigido a don Beltrán de la Cueva, duque de Alburquerque, por alusión a una referencia interna en el f. 39': «lllustre señor ya tengo vuestra mencion del principio de su apellido de la cueba».

El manuscrito contiene una hoja de guarda anterior, donde encontramos en la parte superior derecha una pegatina de color blanco con la signatura actual del manuscrito: F/30, y cinco hojas de guarda posteriores. Está formado por 168 folios

38 Sí aparece catalogado en López Vidriero 1999, 1: 45). 
(285 x $193 \mathrm{~mm}$ ) en los que se distinguen dos foliaciones distintas: una numeración antigua, en tinta, que es la que contiene la mayoría del códice, y una numeración moderna a lápiz, que encontramos únicamente en los folios en blanco $(36,37,97,102$, 106, 122 y 123) y en aquellos que un segundo copista, también de la época, completó porque estaban en blanco (95 y 98). En cuanto a la caja de escritura, la mayoría de las obras están escritas a línea tirada ( $223 \times 155 \mathrm{~mm}$, tomado del f. $1^{\text {r }}$ ) y encontramos alrededor de 29 líneas por plana, aunque pueden oscilar entre 26 y 30, en función de la presencia o no de escudos pintados en muchos de los folios. Por lo que se refiere a los textos poéticos, la Pregunta que hizo el conde de altamira a frai luis de escobar de la orden de sant francisco de los reyes (ff. 144v-146v) ${ }^{39}$ está dispuesta en una columna y 3-4 estrofas por folio, mientras que las obras de Gracia Dei están a dos columnas (ff. $\left.147^{\mathrm{ra}}-147^{\mathrm{vb}}\right)$.

Podemos distinguir, como ya he advertido, dos copistas diferentes en el manuscrito. El primero que identificamos es el que copia, prácticamente, todo el códice, y se caracteriza por una letra humanística «con rasgos de cortesana» (López Vidriero 1999, I: 45). Utiliza, además, dos tipos de calderones distintos, especialmente en la primera parte del manuscrito. Se encarga, también, de indicar en tres ocasiones que «faltan ojas» (ff. 46r, $143^{r}$ y 150v), aunque esta anotación, como veremos, hace referencia no exactamente al número de hojas desaparecidas, sino a pérdidas de materia perceptibles en la lectura del contenido. El otro copista es el que completa los folios en blanco y realiza varias anotaciones marginales; debió de conocer la obra de la que se trataba, el Recogimiento de nobleza, de Alonso Castilla, porque las partes que faltan y que él completa - afectan a los linajes de Urbina y de Peña - son, en efecto, las que encajan al hilo de la obra en el otro testimonio en que se transmiten, el manuscrito 9/271 de la Real Academia de la Historia.

39 Nota marginal a la izquierda de la rúbrica, de la mano que completa el códice: «fue ese frayle el q escribió las quinquagenas q se dizen del almirante». 
El códice contiene numerosos escudos pintados en acuarela, un total de 71 , aunque ambos catálogos -en línea y López Vidriero 1999, I: 45) - consignan 72. La confusión ha debido de darse porque cada escudo está numerado y en el último de ellos encontramos, en efecto, el número 72. Sin embargo, entre el apellido de la Rueda - número 42, f. $105^{\vee}$ - y el de Laso de la Vega (107) hay un salto, porque este último, al que le corresponderá el número 43, lleva, en cambio, el 44. A diferencia de otros manuscritos, en los que podemos encontrar el escudo centrado, debajo de la historia de cada uno de los linajes, en este caso aparecen siempre en los márgenes derecho o izquierdo. En los folios 113 y 133 el escudo se ha recortado, de manera que afecta al texto, tanto en el recto como en el vuelto. En su lugar, se ha insertado un trozo de papel acorde al tamaño del recorte para suplir el hueco; en los ff. $100^{\vee}$ y $129^{r}$ se deja el espacio en blanco para el escudo.

El manuscrito contiene tres filigranas distintas, presentes cada una de ellas en partes diferentes; desde el principio hasta el f. 106 predomina una de ellas: se trata de tres circunferencias con una corona en la parte superior, una cruz latina trebolada en la primera circunferencia y las otras dos en blanco (ff. 3, 5, 6, 11, 12, 15, 19, 21, 22, $27,28,32,33,34,38,40,41,45,49,50,53,54,57,59,62,63,66,69,72,73,77,80$, $81,84,85,88,92,94,95,97,98$ y 106). Esta filigrana no aparece en el repertorio de Briquet, pero sí en el catálogo de Filigranas Hispánicas, y podría corresponderse con la no 0021318A. ${ }^{40} \mathrm{El}$ problema es que esta marca de agua, en este repertorio concreto, está datada posteriormente, a mediados del siglo XVII, por lo que la información no nos resulta muy útil. La segunda de ellas es una mano con los cinco dedos abiertos, del dedo corazón sale una estrella con cinco puntas y en la parte inferior de la palma encontramos inscrita una «V» (ff. 96, 99, 100, 103, 107, 110, 113, 118 y 121). Se

40 Hay otras cinco filigranas que presentan la misma descripción, pero con sutiles diferencias (0012430A, 0031912A, 0013972A, 0015755A y 0018997A). Me he decantado por la que indico en cuerpo de texto debido a que entre la corona de la parte superior y la primera circunferencia hay una corta línea vertical, mientras que en las siguientes la corona aparece adherida completamente al primer círculo, o separada, sin ningún elemento que la una con la circunferencia. 
asemeja mucho a la no 10877 que identifica Briquet, fechada en 1560 en Lectoure. Finalmente, la tercera de las filigranas que aparece se corresponde con la no 13995 de Briquet, fechada en 1550, en Bordeaux. Se trata de una esfera con líneas horizontales y diagonales en su interior; sobre la parte superior de la esfera figura una estrella, mientras que de la parte inferior sobresale una línea que termina con un pequeño círculo. Esta filigrana aparece hacia el final del códice (ff. 124, 130, 131, 132, 135, 136, $140,141,142,143,144,146,147,148,150,151,154,158,160,161,164,165$ y en la tercera hoja de guarda posterior). A la luz de estos datos podemos, por tanto, fechar la copia del códice hacia la segunda mitad del siglo XVI.

En cuanto al estado de conservación, el aspecto más reseñable es que todos los folios presentan manchas de humedad en la parte superior, especialmente desde el f. 9 hasta el final, pero que, en ningún caso, impiden la lectura de los textos. Las contraportadas, tanto la anterior como la posterior, están arrugadas y presentan manchas de humedad. Encontramos pequeños rotos en los ff. 21, 61, 121 y 124.

En contraste con el manuscrito de la Real Biblioteca, esta fuente es muy limitada en cuanto a la transmisión de textos poéticos de Gracia Dei, ya que contiene únicamente dos composiciones:

1. [ff. $147^{\text {ra }}-147^{\text {va }}$ : Coplas que hizo gracia dei | de los Reyes de castilla (fragmento de ID 1942). Ínc: Pelayo fue destaurante [sic] / el oso mato a fabila. Éxpl: son fernando e ysabel / los dos bien abenturados (7x10).

2. [f. $147^{\mathrm{va-vb}}$ ]: Las reinas que an hereda | do en castilla (ID 1943). Ínc: Ygeria nombre le dio / la loba santos exemplos. Éxpl: ysabel en cada cosa / perficion de todas ellas $(1 \times 10)$.

No es extraño que el manuscrito contenga un fragmento de ID 1942, que comienza desde Pelayo con la restauración de España, pues en varios testimonios 
también lo encontramos de esta forma. ${ }^{41}$ El resto del códice contiene parte de una obra de la que da noticia Valverde Ogallar en su tesis doctoral: el Recogimiento de nobleza, de Alonso de Castilla, y que identifica únicamente en un manuscrito de la RAH, con signatura 9/271. En la fuente que aquí nos ocupa no se copia la obra entera, sino que comienza a partir del equivalente al f.143 ${ }^{\vee}$ - línea 10 - del manuscrito 9/271 de la RAH: "La línea de los godos el qual por Requesta de la rreyna Cotilda...». Otra de las diferencias entre ambas fuentes radica en la falta de algunos linajes en el códice F/30: justamente cuando el copista indica que "faltan ojas», en efecto, no encontramos los siguientes linajes, que sí aparecen en el manuscrito 9/271: Medrano, Manueles, Bolaños y Ribadeneira. Finalmente, la fuente del Monasterio termina con el linaje de los Agustinos, mientras que el de la RAH lo hace con el de Cataluña y sus armas. ${ }^{42}$

Como explica Valverde Ogallar (2002: 303), se trata de una composición que mantiene muchas similitudes con el Recogimiento de Armas de Garci Alonso de Torres, ${ }^{43}$ pero también entraña algunas diferencias que la hacen singular: relata una historia del linaje de la Cueba «la cual no coincide con ninguna de las presentes en otros nobiliarios o libros de armas, incluidos los de Torres» (Valverde Ogallar 2002: 301); contiene también la historia de la fundación de la ciudad de Tornai, así como hace alusión a la misa mozárabe que se celebra en Toledo o establece la división de las 10 naciones de los cristianos. Con la identificación de este nuevo manuscrito custodiado

41 Y no desde el rey Atanarico, como es lo más frecuente. Los mss. Il/660 de la Real Biblioteca, h. II. 21 del Monasterio de El Escorial, el F/30 del Monasterio de las Descalzas Reales y el 9/271 de la RAH también transmiten el texto comenzando por el rey Pelayo.

42 En general, puede que ambos manuscritos tengan también relación con un códice custodiado en los fondos de la Real Biblioteca de El Escorial, con signatura II.h.21, puesto que, en su mayoría, recoge las mismas obras. Además, en la mayoría de los manuscritos, la lección del primer verso del poema de las Reynas herederas de España es «Yberia», o «Eugenia», frente a lo que ocurre en el de las Descalzas Reales, el de la RAH y el de El Escorial, en donde se lee «Ygeria». Remito al catálogo de Zarco Cuevas, y también aparece descrito en línea en http://rbmecat.patrimonionacional.es/cgi-bin/koha/opac-detail. pl?biblionumber=335\&query_desc=kw\%2Cwrdl\%3A\%20pedro\%20de\%20gracia\%20dei.

43 De hecho, algunas hipótesis apuntan a que este Alonso de Castilla sería la misma persona que Garci Alonso de Torres (Ceballos-Escalera y Gila 1993: 225). 
en el Monasterio de las Descalzas Reales ya serían, por tanto, dos testimonios los que recogen estos interesantes textos.

\section{MANUSCRITo 9/271, REAL ACADEMIA DE LA HISTORIA, MADRID ${ }^{44}$}

En el nutrido fondo de la Colección de Salazar y Castro de la RAH se conserva un manuscrito que, a la luz de lo expuesto, pudo ser la fuente de la que se valdría el copista del códice anterior. La colección de Salazar y Castro ingresó en 1850 en la RAH, procedente de la Biblioteca de las Cortes, y cuenta con un total de 1498 volúmenes (78584 documentos). El contenido de los manuscritos - tanto originales como copias - e impresos recogen los siguientes temas: Heráldica, Genealogía, Órdenes Militares, gobierno y relaciones internacionales de los reinos de Castilla y Aragón, fueros o privilegios (Alberola Fioravanti 1995: 98-99).

El manuscrito, por tanto, aparece catalogado en los inventarios dedicados a los fondos de este bibliógrafo, como el Índice de la colección de don Luis Salazar y Castro (Cuartero Huerta \& Vargas-Zúñiga 1955, XII: 91-98, no 19807). No encontramos ningún sello o exlibris que nos permita asociar el códice con un poseedor anterior a Salazar y Castro. No obstante, sí podemos rastrear su posible origen: el manuscrito fue copiado por Castilla, rey de armas de Carlos I, tal y como indica en la rúbrica de las Coronicas de Vizcaya: «Suma de las coronicas de Vizcaya y algunos otros linajes de aquel señorio la qual yo castilla Rey de armas del susodicho emperador y Rei nuestro señor halle escritas en un quaderno escrito del de mccc» $\left(48^{r}\right) .{ }^{45}$

Además, tal y como se desprende de una referencia interna, el copista se dirige a Beltrán II de la Cueva y Toledo, III duque de Alburquerque. En la parte final de la historia de este linaje, a propósito de Beltrán de la Cueva - I duque de Alburquerque, el que fuera valido de Enrique IV - , el copista indica lo siguiente: «caso con hija de don diego hurtado de mendoça en la qual engendro al muy ille señor don franco hernandez

44 Da noticia de él Valverde Ogallar en su tesis doctoral (2002: 300-303).

45 Valverde Ogallar, erróneamente, la sitúa en el f. $47^{r}(303$, n. 634). 
de la cueba padre de V. illma ${ }^{\text {ma }}$ ». Y añade a continuación: "Ylle señor ya tengo hecha mençión del prinçipio de su apellido de la cueba y como fueron ganadas sus armas» (f. 185'). Beltrán II de la Cueva también estuvo al servicio de Carlos I, por lo que es probable que ambos se conocieran y, quizá, la compilación del manuscrito fuera un encargo personal del III duque de Alburquerque.

Está encuadernado en pergamino marrón $(295 \times 215 \mathrm{~mm})$, con restos de correíllas en la parte inferior y superior, así como en cuatro ocasiones a lo largo del lomo -superior, inferior y dos en el centro. En el lomo figura el título, debajo de la antigua signatura, C. 48: "RECOGIMI | ento | DE | Nobleça | POR | Castilla Rey de | Armas». En la parte inferior del lomo encontramos una pegatina con la signatura actual 9271 - aunque, en realidad, el 9 debería ir separado por una barra /. Lo único que percibimos en las cubiertas se halla en la anterior: en la parte superior y centrado de nuevo se lee la antigua signatura. ${ }^{46}$

Tanto en la contracubierta anterior como posterior encontramos una hoja de guarda volante que, en el caso de la anterior, cuenta con varias series de números, que hacen referencia tanto a antiguas signaturas como a la actual -12-2-4 y C-48 tachadas; 9-8-1, C-48 y 271 sin tachar. A continuación, dos hojas de guarda y tres folios sin numerar; en el primero de ellos, con una mano diferente a la del copista del resto del códice, puede leerse lo siguiente: «Recogimiento de nobleza por Alfonso Castilla Rey de Armas de los Reyes católicos vse fol 287 y del emperador Carlos quinto vse fol 48 en el titulo de las coronicas de vizcaya». Esta misma mano es la encargada de hacer en la hoja II la tabla de contenidos a modo de índice, donde incluye el título y número

46 Da noticia también de este manuscrito, a colación de la obra de Alonso de Castilla, Menéndez Pidal de Navascués: «En la encuadernación, el texto se titula Recogimiento de nobleza y se atribuye a Alfonso de Castilla, rey de armas de los Reyes Católicos y del emperador Carlos V, personaje del que no conocemos otra noticia. A partir del f. $287^{\vee}$ se copia la obra Blasón de Armas o recogimiento de Armas, de Garci Alonso de Torres, autor bien conocido, que acaso sea la misma persona» (2004: 119). 
de folio, aunque cabe señalar que pasa por alto algunas de las composiciones que figuran en el códice. ${ }^{47}$

El manuscrito, que, según advierten Cuartero Huerta \& Vargas-Zúñiga, "está incompleto, por el final» (1955, XII: 91), está formado por 332 folios (285 x 200 $\mathrm{mm}$ ), en los que conviven dos foliaciones distintas: una en la parte superior derecha, justo en el pico de la hoja que, en ocasiones aparece prácticamente cortada - se correspondería con la numeración antigua, debido al trazo-; la otra se sitúa debajo de la anterior. No obstante, esta segunda numeración no aparece en todos los folios. Los folios presentan pautado a punta de plomo, pero solo en el recto de los mismos, nunca en el vuelto, condicionando, de esta forma, una caja de escritura de $215 \times 140 \mathrm{~mm}$. A excepción de los textos poéticos, el resto de las composiciones están escritas a línea tirada, con un total de 31-32 líneas en cada plana, en función de la presencia o no de escudos.

Cuartero Huerta \& Vargas-Zúñiga datan el códice en 1520 (1955, XII: 91) e indican que se trata del original. Sin embargo, una referencia temporal en uno de los textos, que trata sobre la "Ampliaçion de la çiudad de Granada», nos obligaría a retrasar la fecha de copia un mínimo de seis años: «estando el emperador y rrey nro señor en la çiudad de granada que fue en el año mdxxvi» (f. 272'). Además, el manuscrito contiene la Pregunta que fizo el vizconde de Altamira a fray Luis de Escobar, que forma parte de Las respuestas quinquagenas, impresa por primera vez en Valladolid en 1526, en la imprenta de Nicolás Thierry. Dado que no he sido capaz de localizar filigranas en el papel del códice, debemos limitarnos a establecer 1526 como fecha post quem y 1560 como fecha ante quem, puesto que es el año en que murió el III duque de Alburquerque, personaje al que Castilla se dirige.

Este Alonso de Castilla decidió incluir en el manuscrito dos obras de Pedro de Gracia Dei, las mismas, como venimos advirtiendo, que las que recoge el códice

47 Entre ellas, las composiciones en verso, como la Pregunta que fizo el vizconde del Altamira a fray luis de escobar de la orden de Santiago de los señores de isrrael (ff. 267 va $-268^{\text {ra }}$ ) y los textos de Pedro de Gracia Dei. 
custodiado en el Monasterio de las Descalzas Reales, con idénticas lecturas en aquellos versos más susceptibles de ser alterados por los copistas: ${ }^{48}$

1. [ff. 267va-268 ${ }^{\text {ra }}$ : Coplas que hizo gracia dei | de los rreys de castilla (fragmento de ID 1942). Ínc: Pelayo fue rrestaurante / el oso mato a fabila. Éxpl: son hernando e ysabel / los dos bien aventurados (7x10).

2. [f. 268 ${ }^{\text {ra }}$ : Copla de las rreinas que | an heredado en castilla. Ínc: Ygeria nombre le dio / la loba santos enxemplos. Éxpl: Ysabel en cada cosa / perfiçion de todas ellas $(1 \times 10)$.

Nos encontramos, por tanto, ante un testimonio original de Alonso de Castilla que, si se identifica, como hemos visto, como rey de armas de los Reyes Católicos y del emperador Carlos V, podemos datar, sin lugar a dudas, en una fecha posterior a 1526, pero muy cercana. De ser así, se trataría de la fuente más antigua que transmite composiciones poéticas de Pedro de Gracia Dei. De hecho, si aceptamos que nuestro autor murió en Zafra en el año 1530, como podemos inferir a partir de la Historia genealógica de la casa de los Osorio (BNE, ms. 3449$)^{49}$ es incluso posible que este manuscrito se copiara en vida de Gracia Dei.

\section{MANUSCRITO 58-4-6, BiblioteCA CAPITULAR, SEVILLA ${ }^{50}$}

Si el testimonio de la RAH se nos ofrece como el más antiguo, el que se encuentra en los fondos de la Biblioteca Capitular se erige como uno de los más modernos, ya

48 El catálogo realiza una descripción interna completa, a la que remito para el conocimiento de todas las obras y capítulos en los que se divide (Cuartero Huerta \& Vargas-Zúñiga 1955, XII: 91-96).

49 «Uno de los notables hombres que en nuestros siglos concurrieron destas antigüedades [heráldicas y genealógicas], el cual espiró en mis manos en esta villa de Zafra, á quien el conde (de Feria), mi señor, maguer niño á la sazón, le mandó hacer toda la honra que á tal varón pertenecía». Cito a partir de la transcripción que Gayangos incluye en el prólogo a la edición facsímil del Blasón general y Nobleza del Universo, de Pedro de Gracia Dei (1882: VIII).

50 Agradezco encarecidamente a Francisco José Sáez Guillén, facultativo de la Institución Colombina y autor de los catálogos de manuscritos de la misma, su predisposición y ayuda cuando acudí a consultar este manuscrito. 
que se trata de una copia de principios del siglo XVIII, concretamente fechado en el año 1707, según anota el copista en varias partes del códice. ${ }^{51}$ La encuadernación, en pergamino marrón (215 x 157 mm), presenta la marca de los dos agujeros por los que se introducían las correíllas para cerrar el códice. En la cubierta anterior figuran varias series alfanuméricas: N. 26, 10, 84-4 y E4a...465...9, de las cuales las dos últimas se corresponden con antiguas signaturas del códice. En el lomo, en tinta marrón oscuro, está inscrito el siguiente título: "OBRAS | de | Garcia Dei | y de Saa». En la parte superior al título encontramos el número 9 en tinta negra y en la parte inferior una pegatina de la Biblioteca Colombina, con la signatura actual del manuscrito. En la primera hoja de guarda, está escrita la antigua signatura 84-4-13 tachada y, debajo, a lápiz y sin tachar, la signatura actual. ${ }^{52}$

El códice está formado por 132 folios, aunque se numeran solo 123, a partir del décimo, que es donde empiezan las obras propiamente dichas; a estos hay que añadir dos hojas de guarda anteriores y tres posteriores. Las medidas son de $210 \times 245 \mathrm{~mm}$. Los ff. Iv , IX, 2v $, 3^{v}, 33^{v}, 42^{v}, 70^{r}, 84,115$ y $121^{v}$ están en blanco y entre los ff. 70 y 71 hay un folio sin texto y sin numerar. La foliación, moderna y ubicada en la parte superior derecha, es de la misma mano y tinta que el conjunto del códice. La particularidad de este manuscrito reside, especialmente, en los IX folios iniciales, donde encontramos un prólogo en el que el copista, Diego Ignacio de Góngora, ${ }^{53}$ explica las fuentes de las que se ha servido para confeccionar el volumen:

51 «En el año de 1688 quando se escrivió la copia deste libro, vivía el rey nuestro señor don Carlos Segundo, y en este año de 1707 que se escrive este traslado vive Felipe Quinto» (f. 34^). "Sacóse esta copia en Sevilla año 1707» $\left(85^{r}\right)$.

52 El manuscrito no está recogido en ningún repertorio bibliográfico, ni tampoco en BETA; únicamente encontramos la referencia en el catálogo en línea de la Biblioteca Capitular de Sevilla.

53 He podido documentar, asimismo, otros manuscritos de este fondo copiados también por Diego Ignacio de Góngora en Sevilla en 1707 provenientes de la biblioteca de Felipe Urbano del Castillo, como es el caso del ms. 57-4-7. 
El libro M.S. que me dio para copiarlo Don Phelipe Urbano del Castillo está escrito de letra de Don Fernando de la Saabedra (que conoce muy bien quien esto escrive, porque tiene en su poder otros libros y papeles suyos) quien no fue menos aplicado del estudio de Genealogías y linages, que D. Domingo de Vabizu, el qual compró todos los libros y papeles mss de Don. Fernando de la Sab, y le vendieron sus herederos quando murió el susodicho. Al principio del libro está una nota en que dize que este libro le copió D. Fernando, de uno que le comunicó D. Josef Maldonado Saabedra, que lo habia trasladado de uno que tenía en su librería Nicolás Antonio, Cavallero Del Orden de Santiago, Agente en la Corte Romana del Rey Nuestro Señor D. Phelipe quarto, canonigo de la Santa Iglesia de Sevilla del consejo de su Magestad en el de cruzada, y era del coronista Pedro Mexía. Y lo que yo puedo certificar es que Don. Josef Maldonado me dio un libro, que me dixo era escrito y notado por Pedro Mexía, y estaba en la librería de Don Nicolas Antonio, para copiar dél algunas cosas tocantes á Sevilla, y sus antigüedades, que copie algunas dellas, poniéndoles la nota de que lo saque y traslade de este libro, y en el estaban estas coplas y estancias por de Gracia Dei (ff. II y III).

Por los datos que ofrece y, tras el cotejo con el resto de manuscritos transmisores de la poesía de Gracia Dei, el proceso de transmisión textual hasta el f. $85^{\vee}$ puede explicarse de la siguiente manera: el códice del que se vale Diego Ignacio de Góngora fue copiado por Fernando de Saavedra que, a su vez, tomó como base un manuscrito transcrito por José Maldonado Saavedra. Este último códice al que se refiere Fernando de Saavedra puede corresponderse con dos manuscritos: el 7864 de la BNE y el COD. 1155 de la Biblioteca Nacional de Portugal. ${ }^{54}$ Ambos manuscritos presentan las mismas anotaciones marginales ${ }^{55}$ y no solo incluyen las poesías de Gracia Dei, sino también algunas composiciones de Joan Roiz de Saa, que Diego Ignacio de Góngora dice haber copiado del mismo ejemplar del que se sirvió para las obras de nuestro autor. ${ }^{56}$

54 Recordemos que ambos manuscritos contienen una idéntica anotación: "Obras del savio baron Gracia Dei [...] Copiadas por Don Joseph Maldonado de Saavedra en esta ciudad de Sevilla de un libro antiguo que de diversas materias y cosas de Sevilla junto y escribio el coronista Pedro Mexia, que era de Don Nicolas Antonio Cavallero del Orden de Santiago [...]». Los datos coinciden con los que nos ofrece Diego Ignacio de Góngora.

55 Dichas anotaciones las encontramos en algunos apellidos pertenecientes a los Blasones de las armas e insignias de los mejores y más principales linajes de Castilla y al Vergel de Nobles, ambas composiciones de Gracia Dei, y hacen referencia a otros libros donde podemos encontrar la historia de esos linajes; principalmente se remite a la Nobleza de Andalucía de Argote de Molina.

56 «En el libro que copió Don. Fernando de la Sab, estaban unas coplas de Joan Rois de Saa, de algunos 
La última obra del manuscrito, titulada Vergel de Nobles, también es copia de otro códice, pero por los datos que ofrece el copista no podemos relacionarlo con ningún manuscrito en concreto, ya que algunas composiciones de Gracia Dei se transmiten en varios testimonios bajo este mismo título:

El dicho canonigo me dio un quaderno con titulo de Coplas de Gracia Dei, Rey de armas de los Reyes Catholicos Don. Fernando y Dạ Isavel, llamado Vergel de Nobles, el qual copié y puse a continuazión de las obras de el dicho Gracia Dei, por ser de una misma materia, y un propio autor (f. VIIr).

Respecto a la disposición de los textos, todo el manuscrito se caracteriza por un pautado a punta de plomo muy marcado, lo que condiciona una caja de escritura de $190 \times 80 \mathrm{~mm}$, de manera que todos figuran centrados en la plana, incluido el prólogo - a excepción de las rúbricas, que sobresalen del pautado. Por tanto, queda un espacio en blanco en los márgenes izquierdo y derecho, de aproximadamente 3.5 $\mathrm{cm}$. Las composiciones en verso están dispuestas a una columna y la tendencia es de 22-23 líneas por plana, aunque a partir del f. $86^{r}$, cuando comienza el titulado Vergel de Nobles de Gracia Dei, el copista coloca únicamente una estrofa por folio, la que se corresponde con cada uno de los linajes, que puede oscilar desde los cuatro versos hasta, incluso, los trece, aunque la tendencia es que se ajuste a la extensión de la copla real. Esta disposición implica que los ff. $86^{\mathrm{r}}-123^{\vee}$ presenten más espacio en blanco que el resto de folios. ${ }^{57}$

linajes de Portugal y respecto de haver visto citado este Autor algunas vezes, para comprobación dellos, los copié y puse a continuación de la obra de Gracia Dei, como estaba en el exemplar de donde yo copié este».

57 Esta organización de las estrofas en la última obra se explica porque en el manuscrito del que se copió Diego Ignacio de Góngora así figuraban, como explica en el prólogo: «El dicho quaderno tenia antes de la estancia o coplas de Gracia Dei un blanco a la mitad de cada plana, que pareze devia de ser para poner allí las armas de aquel linaje, o escribir alguna nota o cita que condujese a la mayor claridad de el; lo qual no estaba en las otras coplas de Gracia Dei referidas en sus obras, sino que estaban inmediatas unas tras otras; las de este quaderno y las de sus obras, copié como en el exemplar de Dn. Felipe Urbano las halle». 
El manuscrito se encuentra en buen estado de conservación, aunque podemos encontrar manchas de humedad en las contracubiertas y en algunos folios, si bien no dificultan la lectura de los textos. Lo que sí presenta un deterioro notable es la encuadernación, hasta el punto de que el pico inferior izquierdo de la cubierta posterior está roto. El f. 84 está prácticamente despegado del lomo y en la última hoja, la 123, hay un pequeño agujero en el centro de la hoja.

A excepción de las obras de Joan Roiz de Saa, que ocupan los ff. $71^{r}-85^{v}$, el resto del manuscrito transmite composiciones de Pedro de Gracia Dei. Nos encontramos, por tanto, ante una fuente muy rica sobre la poesía de nuestro autor:

1. [f. 3]: Dedicacion a la Reyna Da Ysavel (ID 6964 ${ }^{\text {bis }}$ I 1942). Ínc: «Muy alta muy poderosa / del mundo mayor señora». Éxpl: «de los sciticos abuelos / vos cuentan los Reyes ochenta» $(1 \times 10) .^{58}$

2. [ff. 4r-9r]: Comienza la obra (ID 1942). Ínc: «Año del omnipotente / de trezientos y cinquenta». Éxpl: «y nuebas gentes hallando / a Napoles recobraron» $(19 \times 10) .{ }^{59}$

3. [f. 10']: Prohemio (ID 6965 bis). Ínc: «Quien los blasones leyere / de la real genealogia». Éxpl: «y mediando cubre clausa / lo que en junta no se alaba» $(1 \times 10)$.

58 Le precede a esta obra una extensa rúbrica: «OBRAS | Del Sabio varon Gracia Dei, criado y Rey de armas delos | mui altos y Catholicos Reyes Don Fernando y Doña Isavel, | invictissimos Reyes de España y despues delos muy | altos y Poderosos Principes Don Felipe y Dá Joana | Reyes de Castilla y Leon. Primeramente se sigue la obra que compuso | de los nombres delos ochenta Reyes Godos que reynaron y las victorias que obieron, | y todo sabiamente hordenado, y puesto en el metro, que en aquel tiempo | se usaba, lo qual fue sacado de la obra que el dicho Gracia Dei | compuso y dirigio a los Reyes Don Felipe y Dạ Joana, de las | excelencias de las Christianissimas Reynas Dạ Isavel y Doña Joana» (f. $1^{\text {r)}) . ~}$

59 Anotación tras la última estrofa: «Lo que en esta ultima copla se contiene se entiende de los Reyes Catholicos Don Fernando y Dạ Isavel: murió la Gloriosa Reyna Dạ Isavel en Medina del Campo martes a veinte y seis de Noviembre de mil quinientos y quatro años: yaze en Granada» $\left(9^{r}\right)$. 
4. [ff. 10v-33']: Reyes Godos (ID 6966 ${ }^{\text {bis }}$ ). Ínc: «Dos leones colorados / de Athanico [sic] animoso». Éxpl: «quien dio tales alegrías / a sus reynos tan lozanos» $(82 \times 10)$.

5. [f. 34r]: Las mujeres que han heredado | los Reynos de España (ID 1943). Ínc: «Eugenia nombre le dio / la loba sanctos exemplos». Éxpl: «Ysabel en cada cosa / perfeczion de todas ellas» (1x10).

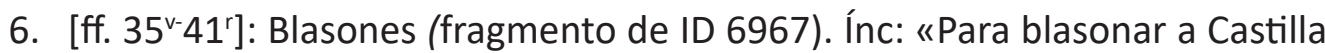
/ es tan alta su substancia». Éxpl: «que la gran Roma del Tybre / nunca se mostro tan bella» $(22 \times 10,1 \times 9) .{ }^{60}$

7. [ff. 42r-69v]: Blasones de las Armas e insignias | de los mejores y mas Principales Linajes | de Castilla: declarando sus principios. | Fechos por Gracia Dei (fragmento de ID 1941). Ínc: «Con parte de las reales / en purpura vi dos piezas». Éxpl: «don Manuel le llamo / legitimo de Castilla» (91×10, 3×13, $2 \times 14,2 \times 9,2 \times 8,2 \times 5$ 1x11).

8. [ff. $85^{r}-115^{r}$ ]: Coplas de Gracia dei | Ilamado Vergel de Nobles (fragmento de ID 1941). Ínc: «Hardides de hombres de guerra / y tambien de cavalleros. Éxpl: Los sublima por mil modos / llenos de mui buena fama $(52 \times 10,3 \times 13$, $3 \times 5,2 \times 8,1 \times 4,1 \times 9){ }^{61}$

Las cinco primeras composiciones se transmiten sin ninguna anomalía reseñable: los textos completos, con las lecturas habituales que encontramos en los testimonios que también las incluyen. Son, en efecto, las obras que menos

60 Tanto en los manuscritos 7864 de la BNE y en el COD. 1155 de la Nacional de Portugal como en el presente códice, bajo el título de Blasones el copista incluye extractos de los Blasones de ciudades y villas.

61 No debemos olvidar que este Vergel de Nobles se corresponde, prácticamente en su mayoría, con los Blasones de las armas e insignias de los mejores y más principales linajes de Castilla, aspecto que advierte el copista del códice: «En el libro de las Obras de Gracia Dei y en este quaderno Vergel de Nobles se repiten las mesmas estanzias y coplas, algunas sin variar nada, y otras con alguna palabra diversa, pero en la substancia es lo mesmo». No obstante, algunos testimonios transmiten bajo el título Vergel de Nobles parte de la Genealogía y blasón de los Reyes de Castilla (ID 6966 ${ }^{\mathrm{bis}}$ ). 
alteraciones sufren, las que se insertan dentro de la historiografía en verso. En cambio, la complejidad reside, como es lo habitual, en los textos heráldicos. En la composición que se corresponde con la $\mathrm{n}$ ㅇ 6, titulada Blasones, el manuscrito transmite las coplas de las siguientes ciudades: Portugal (2), Ávila — se repite dos veces la misma; una de ellas incompleta, pues faltaría el verso 9-, Carrión (2), Tordesillas, Baeza, Salamanca, Zamora, Ciudad Rodrigo, Córdoba, Plasencia, León, Burgos, Astorga, Cádiz, Alcántara, Valladolid, Medina del Campo, Arnani (Hernani), Véjar y Bilbao. Tras la copla de la ciudad de Baeza, el copista anota lo siguiente: «Los que se siguen se hallaron en un libro manuscripto intitulado de la Nobleza compuesto por un Curioso en Toledo año de 1545. Parezen de Gracia Dei» (f. $36^{v}$ ). En efecto, las coplas que «se siguen» pertenecen a Gracia Dei y las encontramos, además, en varios testimonios, como en el conocido MP2 o en los manuscritos 3231, 3449 y 5911 de la BNE.

La particularidad de la composición no 7 reside en las anotaciones que el copista indica al hilo de la redacción, que remiten a diversas fuentes en las que podemos encontrar algunos versos de Pedro de Gracia Dei. Se transmiten las coplas de los siguientes linajes: ${ }^{62}$ Manrique, Lara, el Conde de Osorno (1x13), marqués de Aguilar (1x13), Ponces de León (1x11), Haro (1×14), Guzmanes, Guzmanes de Sevilla, Enríquez (2x10 y 1x8), Manueles, Cerdas, los de Castilla, Mendozas, Ruy Laso de la Casa de la Vega, Castros de Castilla, Duque de Villahermosa, Estúñiga, Velascos, Guevaras, Rojas, Toledo de los Jaqueles, Toledo de las Palomas y del Castillo (1x9), Ávila, Córdoba, Meneses, Pimentel, Portugal, Silvas, Puertocarreros, Coellos, Fonsecas, Pachecos, Acuñas, Bocanegras, Girones, Tellez y Molina, Ayalas, Prados, Sarmientos, Arellanos, Osorios, Quiñones, Carrillos, Cárdenas, Tovar (1x9), ${ }^{63}$ Salazar (2x10), Lunas (2x10), Villandrados, Cueva, Avalos, Padillas (1x13), Herrera, Coronel, Sotomayor, Figueroa, Maldonado, Arze, Cabeça de Vaca, Coronado, Reinoso, Cisneros (2x10), Solier, Barba, Biedma, Leivas, Loçenas, Loaysas, Montoya, Torre, Peraltas, Parage, Espinosa de los

62 Si no indico nada entre paréntesis, la estrofa perteneciente a cada linaje es una copla de diez versos. 63 Falta el verso 8, con el espacio en blanco, al igual que en ms. 7864 y que en 3449, que también tiene 9 versos. 
Monteros, Cartagena, Saldaña, Ciurana, Esquiveles de Viscaya y Villegas de Castilla $(1 \times 14)$.

A continuación, el copista indica que «Lo que se sigue cita Argote de Molina en su Nobiliario de Andaluzia por de Gracia Dei» (f. 63v): se repite Solier y Castro y se añade Salcedo, Andrada y Bracamonte. Después de Bracamonte, Ignacio de Góngora añade otra nota: «También están por de Gracia Dei los siguientes en Argote, aunque imperfectos»: Mendozas (1x5) y Monte (1x8). Indica después que «Mosquera en su Numantina tiene por de Gracia Dei lo siguiente de los Veras»: Veras (1x5). Finalmente, en el f. $65^{v}$, señala que "Los que se siguen son del Libro referido Luzero de la Nobleza»: ${ }^{4}$ Quiros, Osorios, Stuñiga, Carvajal, Trejo, Leyva, Laso de la Vega, Cañizares, Ulloas, Fonsecas, Santillana, Prado, Chaves y Manueles. En la composición no 8, el Ilamado Vergel de Nobles, se repiten muchos de los apellidos de los otros dos textos anteriores. ${ }^{65}$

\section{CONCLUSIÓN}

La identificación de estos cuatro testimonios poéticos supone un considerable avance para el conocimiento de la obra en verso de Pedro de Gracia Dei, pero también para la figura del autor, ya que nos ofrecen datos que no incluye ninguna otra fuente consignada por Dutton y/o BETA. Así, gracias al manuscrito II/660 de la Real Biblioteca, la composición de Las XV preguntas que hiço el papa Julio a Gracia Dei

64 «Cita Dn. Fern.do de la Sab por de Gracia Dei, un libro o quaderno con titulo Luzero de Nobleza; y con el no lo he visto citado, ni se si es el que se dize aquí Vergel de Nobles. Si tubiere alguna certeza deste tratado lo notare aquí».

65 Zeballos (1x4), Veras, Baeza, Salazar, Simancas (1x5), Avilas, Ayalas, Marques del Valle (1x8), Mendozas, Cerdas, Duques de Medinaceli, Toledo, Duques de Alva, Portocarrero, Marques de Villanueva, Marques de Aguilar (1x13), Padillas Adelantados de Castilla (1x13), Ossorios Marqueses de Astorga, Aragon, Duques de Villahermosa, Cardenas, Peraltas, Casa de Lara, Manrriques Condes de Ossorio (1x13), Castros, Ayalas, Manrique de Lara, Velascos, Trexos, Biedma, Bustamantes, Baraona, Avalos, Villegas (1x13), Arze, Maldonado (1x5), Ordóñez, Herreras, Carvajales (1x5), Coroneles, Carrillos (1x8), Esquiveles, Barbas, Salzedos, Prados, De los Tellos, Girones (1x9), Bracamonte, de la Ciudad de Avila, Pimentel, Quiñones, Baraonas (2), Pacheco, Ludeña, Cisneros, Girones Duques de Osuna, Ortizes, Pizarros, Andradas, Marroqui. 
sobre las exçelençias de la reyna doña Isabel deja ser de tradición mono-testimonial, lo que tiene repercusiones ecdóticas; además, el manuscrito nos aporta información de carácter biográfico sobre Gracia Dei que debemos tener en consideración, pues apunta, como hemos visto, hacia una dirección de gran interés en la que habrá que indagar. El manuscrito 9/271 de la Real Academia de la Historia, por su parte, deja abierta la posibilidad de que pudo ser copiado en vida de Gracia Dei, hipótesis que ningún otro testimonio identificado hasta ahora nos permite plantear. De ser así, esto sería una buena muestra de que sus obras se difundieron - y se conocieron - en vida del autor en determinados entornos nobiliarios. Finalmente, los datos que nos ofrece Ignacio de Góngora en el prólogo que contiene la fuente de la Biblioteca Capitular de Sevilla han sido determinantes para poder trazar una posible familia de manuscritos dentro de la tradición textual de Gracia Dei.

Desde el punto de vista bibliográfico, ampliamos con este trabajo los datos existentes sobre las fuentes poéticas de este autor, con lo que ello implica para la catalogación de su obra. El cómputo total de las fuentes poéticas de Gracia Dei asciende, por tanto, a 26: los 4 que cataloga Dutton, los 18 que incorporamos a partir de la base de datos de BETA y los 4 que se han presentado en este trabajo. El elevado número de copias evidencia la importante repercusión que debieron de tener las obras de Pedro de Gracia Dei a lo largo de cuatro siglos, ya que contamos con fuentes datadas desde el siglo XVI hasta el XIX. Esto contrasta, inevitablemente, con la poca atención que ha recibido su obra por parte de los especialistas en poesía de cancionero, reflejada en la ausencia de ediciones críticas y en la falta de estudios concluyentes sobre el complejo corpus poético. Este trabajo, en definitiva, contribuye de manera decisiva a la catalogación de las fuentes poéticas de Pedro de Gracia Dei, no solo por recoger la noticia de los numerosos testimonios de BETA no incorporados por Dutton, sino porque da un paso más, con la localización y estudio de cuatro nuevos testimonios para la obra de este autor. 


\section{Bibliografía CITADA}

AhiJAdo Martínez, José Antonio (2011), «Nuevas noticias sobre el ingreso de colecciones históricas en la Real Biblioteca», Avisos. Noticias de la Real Biblioteca, 17/64, pp. 4-7.

AhiJAdo MARTínez, José Antonio (2012), «El fondo del chantre de Teruel don Joaquín Ibáñez [II]: Noticia biográfica», Avisos. Noticias de la Real Biblioteca, 18/66, pp. 2-5.

Alberola Fioravantı, María Victoria (1995), Guía de la biblioteca de la Real Academia de la Historia, Madrid, Real Academia de la Historia.

BETA (Bibiliografía Española de Textos Antiguos), Universidad de California, Berkeley. http://bancroft.berkeley.edu/philobiblon/beta.es.html [consulta:10/07/2019].

BRIQUET, Charles Moïse (1984), Les filigranes: dictionnaire historique des marques du papier, Hildesheim-Zurih-Nueva York, George Olms Verlag, 4 vols.

Ceballos-Escalera y Gila, Alfonso de (1993), Heraldos y Reyes de Armas en la corte de España, Madrid, Prensa y Ediciones Iberoamericanas.

CuARTERo HuERTA, Baltasar, \& Antonio de VARGAS-ZúÑIgA (1949-1979), Índice de la colección de don Luis de Salazar y Castro, Madrid, Maestre, 49 vols.

DutTon, Brian (1990-1991), El Cancionero del siglo xV (c. 1360-1520), Salamanca, Universidad de Salamanca, 7 vols.

FAULHABER, Charles B. (1983), Medieval manuscripts in the library of the Hispanic Society of America: religious, legal, scientific, historical and literatura manuscripts, New York, Hispanic Society of America, 2 vols.

Filigranas Hispánicas, dir. Carmen Hidalgo Brinquis, Instituto del Patrimonio Cultural de España. https://www.mecd.es/filigranas [consulta: 10/07/2019].

GARcía López, Consuelo (2003), Inventario de los fondos documentales de los Reales Patronatos. Archivo del Monasterio de las Descalzas Reales, Madrid, Patrimonio Nacional.

GrACIA DEI, Pedro de (1489), Blasón General y Nobleza del Universo, Coria, Madrid, 1882, introd. Pascual de Gayangos, ed. facsímil, Badajoz, Unión de Bibliófilos Extremeños, 1993.

JAIME LORÉN, Jose María de (2017), «Noticias de la biblioteca del chantre de Teruel Joaquín Ibáñez García», Cuadernos de Ilustración y Romanticismo: Revista del Grupo de Estudios del siglo XVIII, 23, pp. 21-29.

LABRADOR, José J., et al. (1984), Cancionero de poesías varias : Biblioteca de Palacio, Ms. No. 617 (siglos XV y XVI), Cleveland, Cleveland State University. 
LABRADOR, José J., et al. (1986), Cancionero de poesías varias : Biblioteca de Palacio, Ms. No. 617 (siglos Xv y xvI), Madrid, El Crotalón.

LóPEZ VIDRIERo, María Luisa (dir.) (1994), Catálogo de la Real Biblioteca: Manuscritos, Madrid, Patrimonio Nacional, 6 vols.

LóPEZ VIDRIERO, María Luisa (dir.) (1999), Catálogo de los reales patronatos, Madrid, Patrimonio Nacional, 3 vols.

MANGAS, Natalia A. (2019), "Una fuente de poesía de cancionero: estudio codicológico de MN57», en Pragmática y metodologías para el estudio de la poesía medieval, ed. Josep Lluís Martos y Natalia A. Mangas, Alicante, Universitat d’Alacant, pp. 151-165.

Menéndez PidAl de Navascués, Faustino (2004), "Garci Alonso de Torres. "Blasón de Armas o Recogimiento de Armas" ", en Isabel la Católica en la Real Academia de la Historia, ed. Abraham Rubio, Carmen Manso Porto y Luis Suárez Fernández, Madrid, Real Academia de la Historia, pp. 119-125.

PAZ Y MÉLIA, Antonio (ed.) (1892), Opúsculos literarios de los siglos XIV a XVI, Madrid, Sociedad de Bibliófilos Españoles.

VALVERDE OgalLAR, Pedro (2002), Manuscritos y heráldica en el tránsito a la modernidad: el "Libro de armería» de Diego Hernández de Mendoza, Madrid, Universidad Complutense de Madrid [Tesis Doctoral].

ZARCo CUEVAS, Julián (1924-1929), Catálogo de los manuscritos castellanos de la Real Biblioteca de El Escorial, Madrid-San Lorenzo de El Escorial, Imprenta HelénicaImprenta Real Monasterio, 3 vols. 